\title{
SIMPÓSIO INTERNACIONAL DE FENOMENOLOGIA E HERMENÊUTICA. SOCIEDADE BRASILEIRA DE FENOMENOLOGIA
}

Nythamar Fernandes de Oliveira

Decorridos cem anos desde a publicação das Investigações Lógicas pelo fundador da Fenomenologia, Edmund Husserl, ${ }^{1}$ podemos finalmente celebrar a criação, em Porto Alegre, da Sociedade Brasileira de Fenomenologia, reunindo pesquisadores e professores de diversos centros acadêmicos do País. A Fenomenologia tem se firmado como o mais importante movimento filosófico do século $\mathrm{XX}$, não somente pelas contribuições de filósofos e pensadores - além do próprio Husserl - tais como Max Scheler, Martin Heidegger, Nicolai Hartmann, Karl Jaspers, Hans-Georg Gadamer, Emmanuel Levinas, Jean-Paul Sartre, Maurice Merleau-Ponty, Simone de Beauvoir, Mikel Dufrenne, Paul Ricoeur, José Ortega y Gasset, Michel Foucault e Jacques Derrida, mas ainda pelas influências decisivas deste movimento em outras escolas e tendências contemporâneas, tais como o existencialismo, o personalismo, a hermenêutica, o estruturalismo, a teoria dos atos de fala, a teoria crítica e o desconstrucionismo. A importância desses autores e movimentos ultrapassa os domínios tradicionais da filosofia, como se nota pela presença da Fenomenologia em grandes obras das ciências humanas, das ciências juridicas, das ciências sociais, das ciências naturais e das belas artes e literatura. Apesar da formidável contribuição de grandes pensadores brasileiros, tais como Benedito Nunes, Gerd Bornheim, Emildo J. Stein, Zeljko Loparic, Emmanuel Carneiro Leão, Bento Prado Jr., José Arthur Giannotti, Marilena Chaui e Miguel Reale, somente em setembro de 1999 foi oficialmente criada uma sociedade brasileira de pesquisas em fenomenologia e hermenêutica, com sede na PUC do Rio Grande do Sul, que promoveu no mês de novembro do mesmo

1 As Logische Untersuchungen de Husserl foram originariamente publicadas em dois volumes-- o primeiIo, em 1900, contendo os Prolegômenos para a Lógica Pura, e o segundo, em 1901, com as seis Investigações. Uma excelente tradução da Sexta Investigação para o português está disponivel na coleção "Os Pensadores" (São Paulo: Abril Cultural, 1980), trad. Zeljko Lopanic e Andréa M.A. de Campos. 
ano um evento internacional para celebrar a sua fundação. O Simpósio Internacional de Fenomenologia e Hermenêutica reuniu pesquisadores brasileiros e do Exterior para discutir em foro público questões clássicas da fenomenologia à luz dos debates contemporâneos envolvendo temáticas, tais como a ética e a filosofia política, a filosofia do direito, teoria dos valores, metafísica e ontologia, estética, epistemologia e filosofia da linguagem, psicologia e psicanálise, fenomenologia e as ciências humanas e sociais. Para a abertura do evento foi convidado o Prof. Heinz Leonardy, diretor do Centre d'Études Phénoménologiques, na Universidade de Louvain, na Bélgica, onde se encontram, até hoje, as maiores coleções dos Arquivos Husserl -também parcialmente reproduzidas em Nova Iorque e Freiburg. O escritor Rüdiger Safransky proferiu uma bela conferência sobre o seu mais recente best-seller, Um mestre da Alemanha: Martin Heidegger e seu tempo. Os outros convidados estrangeiros que participaram do evento, Pierre Kerszberg (Université de Toulouse), Donn Welton (State University of New York), Klaus Held (Universität Wuppertal) e Roberto Walton (Universidad de Buenos Aires), assim como o Prof. Leonardy e os conferencistas brasileiros Prof. Zeljko Loparic (Unicamp) e Prof. Emildo J. Stein (PUCRS), gentilmente permitiram que os textos de suas conferências fossem publicados, na integra, neste volume da revista Veritas. Além de celebrar a fundação da Sociedade Brasileira de Fenomenologia, o evento permitiu uma maior integração e interação entre pesquisadores, professores e pós-graduandos de todo o País, assim como o fomento de intercâmbios entre instituições brasileiras e estrangeiras, sobretudo da Alemanha, Argentina, Bélgica, França e Estados Unidos, e em particular da Orbis Phaenomenologicum e do Centre d'Études Phénoménologiques. Maiores informações sobre a Sociedade Brasileira de Fenomenologia podem ser encontradas no website http://ultra.pucrs.br/pgiilosofia/fenom/index.htm

Sociedade Brasileira de Fenomenologia

Brasilianische Gesellschaft für Phänomenologie

Société Brésilienne de Phénoménologie

Brazilian Society for Phenomenology. Comitê Executivo:

Presidente: Prof. Dr. Rui Josgrilberg (UMESP)

Vice-Presidente: Profa. Dra. Claudia Drucker (UFG)

Secretánio Executivo: Prof. Dr. Nythamar F. de Oliveira (PUCRS)

Secretário de Publicações:

Prof. Dr. Ricardo Timm de Souza (PUCRS)

Secretário de Eventos e Projetos:

Prof. Dr. Robson Ramos Reis (UFSM)

Conselho Consultor:

Prof. Dr. Benedito Nunes (UFPA)

Profa. Dra. Creusa Capalbo (UERJ)

Prof. Dr. Emmanuel Carneiro Leão (UFRJ)

Prof. Dr. Ernildo J. Stein (PUCRS)

Profa. Dra. Nelci do Nascimento Gonçalves (UFPB)

Prof. Dr. Zeljko Loparic (Unicamp) 
Membros Hononíficos:

Prof. Dr. Bento Prado Jr. (UFSCar)

Prof. Dr. Carlos Alberto Ribeiro de Moura (USP)

Prof. Dr. Celso Lafer Prof. Dr. Gérard Lebrun, in memoriam

(USP/Aix-en-Provence)

Prof. Dr. Gerd Bornheim (UERJ)

Prof. Dr. Guido Antonio de Almeida (UFRJ)

Prof. Dr. José Arthur Giannotti (USP)

Profa. Dra. Marilena Chaui (USP)

Prof. Dr. Miguel Reale (USP)

Prof. Dr. Renato Cirell Czerna (USP)

\section{Adresse à la Société Brésilienne de Phénoménologie}

Permettez-moi, chers collègues, de formuler les meilleurs voeux à l'occasion de la fondation de votre Société. Je le fais en mon nom propre ainsi qu'au nom de tous mes collégues et collaborateurs des Archives Husserl à Louvain. En cette occasion solennelle je veux rendre hommage à ceux qui m'ont précédé à la direction des Archives et qui m'ont enseigné qu'être bon archiviste consistait moins à conserver et garder qu'à donner et distribuer ses trésors. L'essor de la phénoménologie dans le monde entier doit beaucoup à cette institution qui du haut de ses plus de soixante ans d'existence vous salue et cache mal combien elle envie votre jeunesse.

Ce n'est certes pas un pur hasard que la phénoménologie soit née en Europe, mais il va de la phénoménologie comme de la philosophie dont il n'est pas dit que la Grèce contemporaine en soit la meilleure gardienne. Je dirais volontiers que l'avenir de la phénoménologie appartient à ceux dont la vie connait ce que Husserl appelait la "Not" et dont la vitalité se nourrit des défis du monde contemporain. Votre décision de vous organiser en Société savante est une belle preuve de votre vitalité et les phénoménologues du monde entier comptent sur votre élan et votre jeunesse. Notre avenir est entre vos mains.

A force de nous instruire mutuellement et de partager la même passion pour la leçon "des choses elles-mêmes", ne sommes-nous pas tous devenus des amis au vrai sens du mot? C'est donc très amicalement et plein d'espoir que je m'associe à la joie de la naissance de votre Société.

Rudolf Bernet 